\title{
6. Communicating climate change in the Pacific using a bottom-up approach
}

\section{ABSTRACI}

While scientific evidence in support of climate change is growing, awareness and education about its effects, especially among vulnerable communities, is lacking, due to language and cultural barriers. Communities are unlikely to respond to government policies promoting mitigation and adaptation strategies without an improved perception of climate change risk at a local level. Mapping the flow of information between decision makers and citizens is an important part of this process. This article broadly explores the communication channels that are being used for awareness and knowledge sharing in the Pacific. At its core, the article discusses a way in which participatory media has been piloted to enable community discussion about issues around climate change in the Pacific Islands. The 'bottom-up' approach encourages participation of marginalised groups such as women, youth, and people with disabilities who bring diverse perspectives in content creation. This discursive space enables citizens to share knowledge and acquire better understanding of the impacts on livelihood and culture. However, a strong community network and consistent mentoring support are prerequisites for participatory media to have long term benefits.

Keywords: civil society, climate change, communication, Pacific, participatory media

\section{USHA S. HARRIS}

Macquarie University, Sydney

\footnotetext{
OMMUNICATION has become an integral part of the climate change discourse as scientists, governments and civil society organisations recognise the crucial role of effective communication in raising awareness about the consequences of climate change on all species.
} 


\section{'FAILED’ STATES AND THE ENVIRONMENT}

The link between climate change (ie long-term changes in the climate) and extreme weather events is complex, but it is clear that Earth's climate is changing, as reported by the Intergovernmental Panel on Climate Change (IPCC):

Warming of the climate system is unequivocal, and since the 1950s, many of the observed changes are unprecedented over decades to millennia. The atmosphere and ocean have warmed, the amounts of snow and ice have diminished, sea level has risen, and the concentrations of greenhouse gases have increased. (IPCC, 2013, p. 2)

There is strong scientific evidence suggesting that the world's climate is changing and it is 'extremely likely' the increase in greenhouse gas concentrations is human-induced (IPCC, 2013). Climate change will affect a person's right to enjoy life's essentials. Associated impacts, both currently being experienced and projected, threaten the livelihoods and long-term sustainability of communities, including their food and water resources, health, and protection of homes and heritage (see McNamara \& Gibson, 2009; Patel, 2006; Barnett, 2005). More than 50 percent of the population in the Pacific region lives within $1.5 \mathrm{~km}$ of the shore and many of these countries are less than a few metres above sea level, putting them at extreme risk from sea level rise. Parts of the Western Pacific have experienced the fastest rate of sea level rise in the world at 10mm/year (Secretariat of the Pacific Regional Environment Programme, 2012).

While climate change poses an inherent global threat to humanity as a whole, in the Pacific it is uniquely a human rights issue because of the many stresses that Pacific communities are already facing. Droughts, flash floods, increased intensity of cyclones, increased sea surge, and other extreme weather events are affecting Pacific Islanders. These have huge negative impacts on people's livelihoods, health, education, wellbeing and the local economies, all of which are linked to the Millennium Development Goals. Irregular rainfalls resulting in floods and droughts will affect agriculture production, forcing reliance on imported foods and threatening the livelihood of local farmers.

Despite the growing recognition of the link between human rights and climate change (see Caney, 2008; Sachs, 2008), there has been little intervention from Pacific Island states. The region as a whole has ratified the fewest number of core international human rights treaties. Governments cite customary practices that might clash with human rights principles as their reason for not 
ratifying the treaties. Climate change is an issue of human rights, especially given the concern for the long-term sustainability of some island communities and countries. The right to survival, self- determination, culture and nationality therefore becomes an appropriate lens by which to understand and respond to the impacts of climate change. Other basic human rights, including the right to adequate food, water, health and housing are also enshrined in various human rights conventions.

Climate change affects a community's culture and heritage. As communities move away from their traditional lands, due to rising sea levels and other severe weather patterns, many aspects of their cultural heritage are in danger of disappearing along with their land. Heritage can be considered as both tangible and intangible. Tangible heritage can refer to physical structures including churches, meeting halls and cemeteries, while intangible heritage can entail culture, ceremonies and overall ways of life. Climate change and sea level rise threaten both types of heritage.

Awareness and education about the effects of climate change, especially among vulnerable communities, is lacking due to language and cultural barriers. Communities are unlikely to respond to government policies promoting mitigation and adaptation strategies without an improved perception of climate change risk at a local level. Mapping the flow of information between decision makers and citizens is an important part of this process. What are the relevant channels of communication? Who disseminates the information? What impact is the information having on the general population? These are critical questions for both practitioners and researchers working in the area of climate change. This article broadly explores the communication channels that are being used for education and knowledge-sharing in the Pacific. At its core, the article discusses a case study in which participatory media has been piloted to communicate the impacts of climate change on cultural heritage and livelihood in the Pacific islands. First, an appraisal of current communication channels in the region is undertaken.

\section{Regional channels of communication}

In the Pacific, regional organisations have realised the critical role of communication and are implementing a range of measures to enable information dissemination at various levels. These include developing an integrated approach to climate change policy and disaster risk management with due 
recognition of knowledge dissemination through education, training and awareness campaigns. Largely these use a one-way communication approach. The Secretariat of the Pacific Regional Environment Programme (SPREP) has identified awareness as an important link in key climate change issues such as adaptation, mitigation, science and acidification. SPREP has flagged several challenges at a regional level in relation to awareness programmes. These include attempts to ensure that scientifically correct and consistent messages and programmes are maintained; that they are site and community specific; and that they are less dependent on funding cycles (SPREP, 2012). A Pacific Climate Change portal is being developed by SPREP to act as a hub for climate change information and knowledge sharing (www. pacificclimatechange.net). It provides a wide range of resources including an events calendar, links to documents, databases, image and video gallery and glossary definitions that are hyperlinked to key terms. The Pacific Adventures of the Climate Crab and Cloud Nasara are animations intended to increase awareness of the science and impacts of climate variability in the Pacific with specific focus on how to prepare for future El Niño and La Niña events and adapt to climate change.

Various toolkits have also been developed by regional organisations. The Secretariat of the Pacific Community (SPC) has developed a gender and climate change toolkit for use by practitioners working on climate change programmes. The toolkit is designed as a guide to understand the links between gender and climate change in specific sectors such as food security, water, energy and disaster risk reduction by applying the 'gender lens' to relevant case studies, as well as providing a gender analysis checklist (SPC, 2013). The Red Cross Red Crescent has developed a guidance note for its staff and volunteers on how to communicate climate change for risk reduction in the Pacific. Some of the communication principles it espouses include:

- Using two way communication,

- Identifying trusted male and female champions

- Planning practical activities

- Starting with people's own lived experience

- Acknowledging and respecting local beliefs, values and practices. (www.solutionexchange-un.net/repository/pc/ccd/Communicating-Climate Change.pdf). Pacific Solutions Exchange, a UNDP initiative, is a dynamic knowledge-sharing forum which encourages dialogue amongst its member- 
ship. Members post queries on specific topics and share answers, insights, experiences and lessons learned to help their counterparts in the Pacific (www.solutionexchange-un.net).

Media channels which include radio, television and newspapers provide an important service during severe weather events such as cyclones and floods by offering regular updates from relevant authorities (PACMAS, 2013). However, climate change stories receive sporadic coverage, picked up from wire services which use established scientific frames adopted by media globally. Journalists recognise that with proper training they would be able to improve climate change reporting, especially in translating technical terms for the general public (PACMAS, 2013). PACMAS has funded communitybased projects on climate change through its Innovation Fund (one of these projects is the focus of this article). The Pacific Centre for Environment and Sustainable Development (PACE-SD) at the University of the South Pacific uses a participatory approach to research, engaging communities in mitigation and adaptation. It has also designed factsheets on issues relating to climate change for dissemination through media, community networks and schools.

Non-government organisations and church-based organisations play a significant role in encouraging community action through awareness-raising campaigns. Churches in the Pacific are acutely aware that the overall wellness of the Pacific people will be affected by climate change impacts and are demanding that it be treated as a justice issue (Rika, 2013). Regional ecumenical organisation, Pacific Conference of Churches (PCC), has taken a strong leadership on the issue. It has implemented advocacy and awareness programmes on climate change through its network of church leaders, women and youth organisations. PCC represents the churches at all levels in the Pacific Region. Its work involves educating member churches about the impacts of climate change and relevant international policies; advising governments and affected communities on issues of resettlement; advocating for the region based on Christian principles of compassion and social justice (pacificconferenceofchurches.org). The Pacific Theological College also theologises climate change in its teaching through its curriculum so that ministers and seminarians leave with an ingrained understanding of climate change issues.

\section{Review of research}

Research in climate change communication seeks to understand public perceptions of climate change as well as the barriers to attitude and behaviour 
change in relation to mitigation and adaptation strategies. Climate change information enables people to recognise the validity of climate change and the ways in which it is linked to human activity. Effective communication can improve people's knowledge of how their actions contribute to global warming and the impact it has on their livelihoods, health and cultural heritage. Training and education programmes actively engage citizens to find sustainable solutions by participating in mitigation and adaptation.

Research in the area of climate change communication has concentrated on media reporting of climate change by studying how media frame the issue and the attention that media give to the issue (see Schäfer, Ivanova \& Schmidt, 2012; Carvalho, 2010; Zhao, 2009; Boykoff \& Boykoff, 2007; Farbotko, 2005). Fitzgerald undertook an exegesis of her own reporting of climate change to demonstrate how framing devices are used to bring attention to certain issues and not others. She explains:

I constructed my pieces to present a certain point of view or meaning: that climate change is a major issue that will have serious consequences; and that it needs to be combated through social, political and economic action. The framing of each piece deliberately avoided any debate on the validity of the science of climate change itself. (2013, p. 204)

Less frequent are studies that expand our understanding of the different communication channels' roles, as Olausson observes, 'in shaping how citizens understand climate change' (Olausson, 2011, p. 282; also see Falaki \& Adegbija, 2013). In other words, most research has looked at media content and not audience reception of the content or engagement in content creation. The task of tackling climate change impacts and risks needs to be considered in new, creative ways that involve effective collaboration and whole-of-community participation.

Climate change researchers have identified involvement of local communities as a crucial element in implementing and sustaining appropriate adaptation strategies (Nunn, 2009; Dumaru, 2010). The International Union for Conservation of Nature (IUCN) report recommended the inclusion of affected communities 'in the international, regional and local climate change discourse, and that an increasing focus on investigating, documenting and disseminating traditional adaptation strategies to climate change is adopted' (Macchi, 2008, p. 59). Researchers working in Fiji's Rewa River Delta have clearly stated, 
'Adaptive strategies in developing countries can be implemented successfully only through community empowerment, to which an understanding of the perceptions of climate risk is essential' (Lata \& Nunn, 2010).

McNamara's (2013) exploratory study seeks to understand how awarenessraising activities might be conducted 'in a more relevant, meaningful and empowering way at the community level in the Pacific' (p. 864). The study engaged ten climate change practitioners in a focus group discussion on ways to effectively build awareness and engage communities. The practitioners favoured a participatory approach to awareness-raising and a move away from the 'one-way communication paradigm'. They felt that participatory approaches were 'extremely effective' and identified various ways of involving community members such as the development of seasonal calendars, communal storytelling, poem and song competitions, and the use of books and movies (p. 868).

Communication for Development (C4D) practitioners use diverse forms of communication to facilitate participation. These may include interpersonal modes such as community dialogue; various forms of media such as community radio, participatory video, digital storytelling; entertainment education including television and radio dramas, animation, theatre, and music; information and communication technology (ICT) including mobile phones and the internet (Lennie \& Tacchi, 2012).

\section{Participatory approaches in climate change communication}

Participatory video is one form of communication which enables dialogue within and between communities as well as with decision makers. As such, it is a form of public sphere which invites participation of diverse peoples, thus bringing valuable perspectives of marginalised groups such as women, youth, and people with disabilities. This form of public sphere is still under- used in the Pacific, but it may prove to be a viable discursive space in which to engage communities about climate change issues. Projects are designed as bottom-up initiatives which enable integration of indigenous narratives and cultural practices. The process of production helps a community to understand immediate risks from climate change by recording changes to their environment and its impacts on their everyday life. Through dialogue with other community members, discussions with environmental experts and by researching traditional adaptation methods they learn how to plan for the future. 
Digital narratives have also offered a powerful form of storytelling as more people gain access to low-cost digital still cameras. The narratives have strong links to the tradition of oral storytelling. Content may include personal stories, myths and legends, historical events or social change messages which are then placed on online distribution sites. They may be produced in the form of video stories, photographic journals, or a combination of visual, music and sound effects for more high-end productions. Each story is no more than 2-5 minutes in length. Digital narratives are a powerful way for people to capture the everyday life and concerns of a community. For example, village elders can share the important history and heritage of their village with the younger generation and the wider Pacific community.

Community radio is another effective medium which has enabled participation of vulnerable communities in climate change communication. A study undertaken in Malawi looked at the role of radio in promoting community participation in community-based adaptation programmes. It found that participatory radio in the form of radio listening clubs provided a viable public sphere where communities exchanged knowledge and information about climate change and decided on mitigation strategies to build community resilience (Khonje, 2011). More research is needed in the Pacific on how radio can be successfully integrated as a communication strategy in climate change education and community-based adaptation.

Outcomes from this form of community agency include the ability of communities to influence decision makers on climate change policy and exchange information with other communities who are experiencing similar challenges. Agency is the capacity of human beings to act upon their environment in order to bring about change once they become aware of needs in their community. It is a process of conscientisation (Freire, 1984) as well as a result of it. The act of producing the message becomes empowering in itself as participants develop a range of media competencies such as technical and creative production skills, analytical skills in reading mass media texts, and a deeper understanding of their own communicative potential (Riano, 1994) as demonstrated in Table 1 next page.

\section{Role of facilitators}

Facilitating participatory video is a special skill which requires an understanding of participatory methodology, media production skills and a respect for community perspectives. A facilitator has to let the ideas 
‘FAILED' STATES AND THE ENVIRONMENT

\begin{tabular}{|c|c|}
\hline $\begin{array}{l}\text { Does the PV process facilitate the } \\
\text { following outcome? }\end{array}$ & $\begin{array}{l}\text { Evaluate the outcome through the following video training } \\
\text { and production exercises. }\end{array}$ \\
\hline \multicolumn{2}{|l|}{ Dialogue } \\
\hline $\begin{array}{l}\text { Respect awareness of the 'other' } \\
\text { and reflective listening. }\end{array}$ & $\begin{array}{l}\text { Video making is a team activity which encourages listen- } \\
\text { ing to each other's ideas with respect. }\end{array}$ \\
\hline $\begin{array}{l}\text { Consensus building } \\
\text { Communication among members } \\
\text { and with others in the community }\end{array}$ & $\begin{array}{l}\text { Script development process. Choice of stories and loca- } \\
\text { tion, placement of camera, choice of shots, and editing } \\
\text { decisions about what and who to include in the finished } \\
\text { programmes }\end{array}$ \\
\hline Information sharing & Screening and dissemination of the finished programme \\
\hline \multicolumn{2}{|l|}{ Self-representation } \\
\hline Self-expression & Video as a mirror - speak directly to the camera sharing \\
\hline $\begin{array}{l}\text { Self-reflection and feeling of em- } \\
\text { powerment }\end{array}$ & Group viewing session — reactions to the footage \\
\hline $\begin{array}{l}\text { Finding a voice and expressing } \\
\text { opinions }\end{array}$ & $\begin{array}{l}\text { Taking ownership of storytelling during the production } \\
\text { process and interview sessions }\end{array}$ \\
\hline \multicolumn{2}{|l|}{ Capacity building } \\
\hline Media literacy skills & Understanding the role of media in society \\
\hline Critical thinking & Expressing one's own views of mainstream media \\
\hline Creative skills & Learning about television aesthetics \\
\hline $\begin{array}{l}\text { Technological knowledge } \\
\text { acquisition }\end{array}$ & $\begin{array}{l}\text { Use of technology - camera training, microphone } \\
\text { technique, tripod placement }\end{array}$ \\
\hline Public speaking & Presence on camera and interview skills \\
\hline \multirow{3}{*}{$\begin{array}{l}\text { Community building } \\
\text { Inclusion - acknowledgement of } \\
\text { each person as valuable irrespec- } \\
\text { tive of gender, class or ethnicity }\end{array}$} & \\
\hline & $\begin{array}{l}\text { The production process - contribution of ideas, skills and } \\
\text { knowledge by each participant. }\end{array}$ \\
\hline & Reflecting diversity in content production \\
\hline Collective action & $\begin{array}{l}\text { Collaborative process of story development and location } \\
\text { shoot and the inclusion of social networks }\end{array}$ \\
\hline $\begin{array}{l}\text { Community development and } \\
\text { consciousness-raising }\end{array}$ & $\begin{array}{l}\text { Knowledge-sharing through distribution of programme } \\
\text { content }\end{array}$ \\
\hline
\end{tabular}

Note: Developed by Harris (2008) with information sourced from White (2003); Shaw and Robertson (1997).

come from the people - an organic process that feeds off the dynamism of the group process. A crucial role of the facilitator is to create a road map and provide a structure for the workshop (Shaw \& Robertson, 1997), but in a way that would allow others' ideas to be integrated. Participants must

PACIFIC JOURNALISM REVIEW 20 (2) 201485 
be encouraged to use the equipment immediately and begin shooting exercises on the first day of training. The point is not to overwhelm them, but to give them skills in small bite-sizes whereby they can experience a sense of achievement. The importance of storytelling usually overtakes the fear of technology (Harris, 2008). Braakman and Edwards (2002) warn that the facilitator should be 'content neutral', thus not having a stake in the outcome, yet strong enough to ensure a process which invites the participation of all involved and moves the group towards a common goal. As such the facilitator's role is one of 'enabling others' while maintaining the flexibility to relinquish his/her expert role and 'become co-learners in projects' (White, 2003, pp. 39, 45).

The following case study provides insights into a participatory video workshop which explored how this form of media could be used as a tool to empower communities in the Pacific who are already feeling the impact of climate change.

\section{The project — Piloting Participatory Media: A tool of empowerment}

The eight-day workshop was organised by the Pacific Gender Climate Coalition (PGCC) for its facilitators, who work with communities on climate change in the Cook Islands, Fiji, Guam, Kiribati, Niue and Papua New Guinea. The training took place at the Centre for Appropriate Technology and Development at Nadave in Fiji. PGCC is an NGO which aims to incorporate a C4D approach in its work with vulnerable communities which are impacted by climate change in the Pacific Islands. The pilot was designed to extend the participants' knowledge of participatory media as an effective and rich learning tool to find new strategies on community-based adaptation. In the second phase of the project the PGCC facilitators were to train a core group of women in various rural and village settlements where they work. The women would keep track of climatically-induced changes in their environment by using cameras. The lessons learned from the project would build resilience in the communities and also improve their adaptive measures to the impacts of climate change.

\section{Equipment}

Each of the four teams received a complete video kit and a Macbook Pro laptop with iMovie editing software, which gave them the capability to produce quality videos on their return home. In choosing the equipment, workshop 
facilitators were mindful of the locations and communities that would use it. The most interesting feature of the camera is a built-in projector allowing communities who don't have television sets to review the footage, an important aspect of PV methodology, by projecting it on any plain surface. Other features include hybrid storage for in-camera flash memory and an external SD card, as well as a built-in GPS, which detects where the camera is located when filming, an especially significant asset for climate change work. Other items in the kit included a waterproof digital still camera for underwater photography, and a Zoom digital recorder for audio-only recording. Each set of gear came with a waterproof/shockproof carrying case for easy transport and storage. Lessons emphasised the importance of equipment care and safe storage.

\section{Method}

Learning outcomes of the media training were as follows:

- Gain familiarity with Communication for Development (C4D) and participatory media principles in message creation.

- Attain critical thinking skills by engaging in collaborative story development exercises which highlight climate change adaptation, local knowledge and community participation.

- Improve public speaking skills by conducting interviews and recording narrations.

- Gain proficiency in the use of digital technology, including operation of digital video cameras, microphones and other audio and video accessories.

- Acquire basic skills in postproduction such as logging, editing pictures and sound, and adding narration, music and graphics.

The participants were well informed about climate change issues in the Pacific and came from a diversity of professional backgrounds, including marine biology, law, education and media, bringing a mix of perspectives to enable informed discussions. The workshop consisted of discussions, handson training with video and audio equipment and collaborative group work. There were four sessions per day, each having a particular focus on building media literacy and technological skills. Participants actively engaged in production and post-production exercises while they developed climate change themes for short video stories. Activities enabled participants to become confident in the use of video and audio equipment and editing software so that they could return to their own communities and involve them in content 


\section{‘FAILED’ STATES AND THE ENVIRONMENT}

creation. Throughout the workshop there was genuine interest in gaining cross-cultural knowledge, with participants from different Pacific Island countries sharing their experiences with each other, finding cultural similarities in food preparation and discussing adaptation strategies. Two media students from Fiji National University (FNU) were invited to work alongside the participants as production assistants. This created a two-way exchange of knowledge, with the students supporting the participants in production exercises while increasing their own understanding about climate change issues. The author was the lead facilitator of the workshop and was supported by a second facilitator, Martha Mollison, who is an accomplished community video producer.

On the first day, participants were introduced to some of the key terms and concepts such as participatory media and Communication for Development. They were specifically asked to consider what the term participation meant to them; consider some of its challenges; identify their own methods of working with the community; and how they may be able to integrate participatory approaches to their work on climate change.

On the second day, the group was asked to collaboratively identify key themes/topics on climate change. They then divided into teams of two to develop story ideas. Hands-on training in all aspects of video production skills and digital editing continued throughout the week. For their final project, each participant identified a community with whom they could produce a five to ten minute story exploring a climate change theme. Viewing sessions, an important part of the PV process, allowed participants to provide feedback on both the technical and content aspects of each other's work-in-progress, as well as enjoying a sense of achievement.

Some participants noted that the workshop session was too short and they would have liked more time learning how to become proficient in the use of various media tools and in gaining greater editing skills. This aligns with SPREP's concern that programmes are tied to funding constraints. A follow-up workshop within three months of the first training was suggested at community level. This would ensure that the coordinators' skills were refreshed and passed on to other community members. Unfortunately lack of funding has precluded this follow-up workshop.

\section{Production Outcome}

Five group projects were completed on climate change-related topics and 
shared with the group for dissemination and training purposes. These were also uploaded on YouTube as shown in Figure 1 on the following page.

\section{Discussion}

Responses of workshop participants on project evaluation highlighted the capacity building aspects of the PV training. Generally, participants agreed that the training had taught them what participatory media is, how it can be used in community-based content creation and how participatory communicators can make 'a big difference in the lives of people facing gender inequality and climate change issues'. Since they already had a high level of awareness and knowledge of climate change in their own communities, participants identified the 'hands-on' practical aspects as being of greatest value to them. One participant stated: 'Mainly the valuable lesson I learned was to use video to teach what I know in a more exciting way...to communicate the messages we have been trying to disseminate to the communities without much success'. While video was a useful tool of communication, they recognised that the message produced must be clear.

When asked if the training had led to changes in awareness, skills and knowledge, participants spoke about the insights they gained in using different types of communication in transferring knowledge about climate change. For one, the shift was 'from print to video'. Another who had worked as a television journalist realised that the participatory approach had 'taught me to think about letting the community dictate what the story angle is and then let them tell it in their own words and decide how it should be told. They lead, we follow...'. Another noted that conducting interviews in public had improved his confidence in public speaking. One of the students who acted as production assistant on the training acknowledged that before the training, she 'hadn't the slightest idea' that climate change was a big issue in the Pacific, but the training had broadened her 'knowledge on how it can actually change the lives of so many people, the way they live and how they had to adapt to the evolving world due to climate change'.

Two of the participants who produced instructional videos (on virgin coconut oil and poultry farming) understood how this type of production could be used as a teaching tool to improve communities' income-generating and livelihood capacities and as a catalyst for the economic empowerment of women. They recognised that these videos could be localised and replicated 


\section{Figure 1: The five group video projects}

We Will Not be Moved (6 min): This shows climate change impacts on the community's everyday life and culture in the village of Namata in Fiji. youtube.com/watch?v=-mezyqw81EY

Virgin Coconut Oil (11 min): A step-by-step training tape which explains how to produce virgin coconut oil, a sustainable cottage industry gaining favour in the Pacific Islands. youtube.com/rEe7hci4jWc

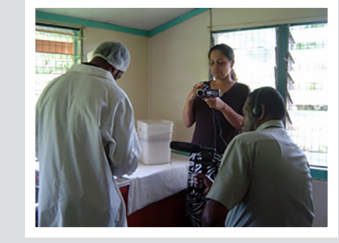

Poultry Farming-Eggs and Broilers (11min): An instructional video which gives a comprehensive lesson in poultry farming for broiler chicken and egg production. From the size of sheds to the daily routine of farm assistants, this film has enough information for anyone who wants to begin poultry farming.

youtube.com/watch?v=HDZw0S6vPgE.

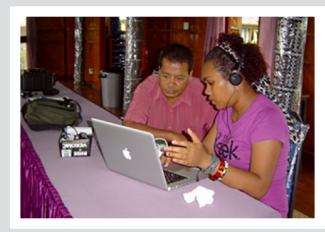

Helping Youth Help Themselves (9min). This video provides an upbeat view of the many strands of practical training (including carpentry, welding, horticulture and animal husbandry) available to young men at the Centre for Appropriate Technology and Development at Nadave in Fiji. youtube.com/watch? $=m A u d-X c-x C g$

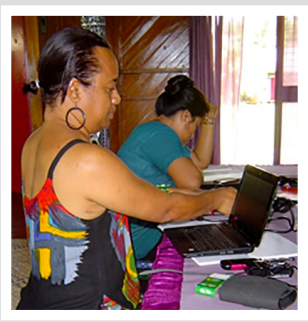

Meaningful Connections-Reviving the Art of Drummaking (3min): A digital storytelling format to capture the art of drum-making in Fiji. The cross-cultural knowledge exchange would assist in a possible revival of the cultural instrument - the drum - in Niue for the purpose of strengthening culture.

youtube.com/watch?v=QV3_1iEjyCo

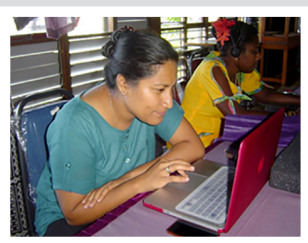


in different communities according to their own needs as impacts of climate change continue to affect food resources in island communities.

Discussion of content from two videos is undertaken here to demonstrate how participatory video can raise awareness about the impacts of climate change on coastal communities, and become a tool for knowledge sharing. We Will Not Be Moved highlights the concerns of people in Namata village in Fiji as they consider the consequences of rising waters on their everyday life and possibility of relocation to higher grounds. The village chief explains the historical context of the village, which informs viewers about the intrinsic connections between culture and geography. Gender perspectives are highlighted as women describe the diminishing fish stocks, which are their main form of income generation. Mothers describe the dangerous conditions facing their children as they navigate a flooded path to catch the bus to school and express their inability to use their outside kitchen during high tide. Some villagers want to move to higher ground while others fear that a move would lead to the loss of important cultural heritage and consequently their identity as a community. The second video, Virgin Coconut Oil (VCO), is an instructional video which demonstrates a step by step process in making VCO. The video recording took place at Nadave Training Centre's manufacturing facility. The producer had seen other videos which missed various steps and wanted to show the whole process in detail. With global interest in the use of virgin coconut oil, this video captured the interest of viewers all over the world with a phenomenal 55,000 views on YouTube and many positive comments.

Upon their return home, participants planned to include communities in the production of content through organised awareness campaigns and consultations, by encouraging community members to share their stories, such as a 'then and now' approach, looking at how things have changed over time through the eyes of village elders. This may include evidence of coastal erosion and its impact on heritage sites by comparing old and new photographs, and the ways in which communities have adapted to these changes. Participants' ideas on ways to sustain production efforts included: to establish technical support including personnel; to fully integrate the training objectives to as wide an audience as possible; to find adequate middle to long-term seed-funding arrangements; to ensure care of equipment and timeliness of production. Another important aspect of this workshop was a commitment by the participants that they would share their skills in camera and editing with two other people in their local area or area of expertise, so that the knowledge would not be lost. 
Ethical issues, such as gaining consent from communities and individuals, were explained. Since the participants understood the traditional protocols of their own community one member explained that instead of seeking written consent from every individual a communal consent is usually granted by the village chief in a sevu sevu, or kava ceremony, in Fiji when a visitor states his or her reason for visiting the village. Participatory video training is normally conducted with members of a community and the process of reviewing footage and consequent feedback ensures communal consent. Participatory media works best when it is implemented in communities with a strong communitybased network. The implementing NGO needs to develop a consistent plan at a regional level with clear guidelines regarding output and dissemination. Participatory projects also require a strong champion who can lead the community in shaping ongoing projects.

\section{Conclusion}

This study looked at how participatory media can be used as a tool to communicate climate change risks and adaptation through the process of message creation. Using a bottom-up approach which involves people who are directly impacted by climate change, participatory media ensures greater representation of community voices in national policy development and international forums about climate change. The case study cited here demonstrates that communities and practitioners are able to share knowledge and information about adaptive measures, and learn new communication skills which assist in increased understanding of climate change. It also encourages intergenerational involvement by inviting young people to work with more knowledgeable older members of the community. Digital narratives are a powerful way for people to capture the everyday life and concerns of a community. Participatory communication tools such as videos, still cameras and audio recording empowers communities facing climate change risks to record their living culture for future generations, ensuring that it is not lost amidst the rising tide of uncertainty.

\section{Acknowledgement}

The participatory media training was funded through the PACMAS Innovation Fund. Thanks to the PGCC participants for their evaluation feedback. 


\section{References}

Barnett, J. \& Campbell, J. (2010). Climate change and small island states: Power, knowledge and the South Pacific. Earthscan, London.

Barnett, J. (2005). Titanic states? Impacts and responses to climate change in the Pacific Islands. Journal of International Affairs, 59, 203-219.

Boykoff, M. T., \& Boykoff, J. M. (2007). Climate change and journalistic norms: A case-study of US mass-media coverage. Geoforum, 38(6), 1190-1204.

Braakman, L. \& Edwards, K. (2002). The art of building facilitation capacities: A training manual, video and self-study CD. Bangkok: Regional Community Forestry Training Center (RECOFTC).

Caney, S. (2008). Human rights, climate change, and discounting. Environmental Politics, 17(4) 536-555.

Carvalho, A. (2010). Media(ted) discourses and climate change: A focus on political subjectivity and (dis)engagement. WIREs Climate Change, 1(2), 172-179.

Dalavera, L \& Obimae, V. (2009). Relocation extreme but necessary adaptation measure. Wansolwara, Journalism Division, University of the South Pacific, 14, 3.

Dumaru, P. (2010). Community-based adaptation: enhancing community adaptive capacity in Druadrua Island, Fiji. WIREs climate change, 1, 751-763.

Falaki, A. A. \& Adegbija, M. V. (2013). Investigating the use of the media in disseminating information on climate change in north central Nigeria. Global Media Journal African Edition, 7(1),13-39.

Farbotko, C. (2005). Tuvalu and climate change: Constructions of environmental displacement. The Sydney Morning Herald. Geografiska Annaler: Series B, Human Geography, 87, 279-293.

Fitzgerald, B. (2013). Climate change reporting in an Australian context: Recognition, adaptation and solutions. Pacific Journalism Review, 19(1), 203-219. Retrieved on August 19, 2014, from http://search.informit.com.au.simsrad.net.ocs.mq.edu. au/documentSummary; $\mathrm{dn}=336718979621808$;res=IELHSS

Freire, P. (1970). Pedagogy of the oppressed [Translated by Myra Bergman Ramos]. New York: Herder and Herder.

Harris, U. S. (2008). Transforming images: Participatory video and social change in Fiji. Unpublished doctoral thesis, Macquarie University, Sydney.

IPCC, (2013). Summary for Policymakers. Climate change 2013: The physical science basis. Contribution of Working Group I to the Fifth Assessment Report of the Intergovernmental Panel on Climate Change [Stocker, T.F., D. Qin, G. K. Plattner, M. Tignor, S. K. Allen, J. Boschung, A. Nauels, Y. Xia, V. Bex \& P.M. Midgley (eds.)]. Cambridge University Press, Cambridge, United Kingdom and New York, NY, USA.

Khonje, Z. (2011). Participatory radio and the public sphere: The case of climate change communication in Malawi. Retrieved July 18, 2014, from: www.genderlinks.org.za/article/participatory-radio-and-the-public-sphere---the-case-ofclimate-change-communication-in-malawi-2012-02-19.

Lata, S. \& Nunn, P.D. (2011). Misperceptions of climate-change risk as barriers to climate-change adaptation: A case study from the Rewa Delta, Fiji. Climatic Change, 110, 169-186. 


\section{'FAILED’ STATES AND THE ENVIRONMENT}

Lennie, J \& Tacchi, J (2013). Evaluating communication for development. A framework for social change. Routledge: London.

Macchi, Mirjam, et al. (2008). Indigenous and traditional peoples and climate change. Issues Paper. Gland: IUCN. Retrieved on February 18, 2011, from: http://cmsdata. iucn.org/downloads/indigenous_peoples_climate_change.pdf.

McNamara, K.E. \& Gibson, C. (2009). 'We do not want to leave our land': Pacific ambassadors at the United Nations resist the category of 'climate refugees'. Geoforum, 40, 475-483.

McNamara, K.E. (2013). Raising awareness about climate change in Pacific communities. Environmental Education Research, 19(6), 864-871.

Nunn, P.D. (2009). Responding to the challenges of climate change in the Pacific Islands: management and technological imperatives. Climate Research, 40, 211-231.

Olausson, U. (2011). 'We're the ones to blame': Citizens' representations of climate change and the role of the media. Environmental Communication: A Journal of Nature and Culture, 5(3), 281-299. DOI: 10.1080/17524032.2011.585026.

PACMAS (2013). PACMAS State of Media and Communication Report 2013. Retrieved on November 15, 2013 from: www.pacmas.org/profile/pacmas-state-ofmedia-and-communication-report-2013

Patel, S. (2006). A sinking feeling. Nature, 440, 734-736.

Riano, P. (Ed.) (1994). Women in grassroots communication. Thousand Oaks, Ca: Sage Publications.

Rika, N. (2013). Climate change is a justice issue for Pacific people. Pacnews. Retrieved on May 28, 2014, from: www.pina.com.fj/?p=pacnews\&m $=$ read\&o=8 $12058780527 b 13 b 72 d c e c 48 \mathrm{e} 18 \mathrm{~d} 0 \mathrm{c}$

Sachs, W. (2008). Climate change and human rights. Development, 51, 332-337.

Schäfer, M. S., Ivanova, A., \& Schmidt, A. (2012). Media attention for climate change around the world: Data from 27 Countries. Paper prepared for the Culture, Politics, and Climate Change conference at the University of Colorado Boulder, Sept 13-15, 2012.

Secretariat of the Pacific Regional Environment Program (2012). Pacific climate change portal: Theme 4: Education, training and awareness. Retrieved on January 17, 2014, from: www.pacificclimatechange.net/index.php/themes/education

Secretariat of the Pacific Community (2013). Pacific gender \& climate change toolkit. Retrieved on December 14, 2013, from: www.pacificclimatechange.net/index.php/ eresources/documents?task $=$ showCategory\&catid $=137$

Shaw, J. \& Robertson, C. (1997). Participatory video : a practical approach to using video creatively in group development work. London: Routledge.

UAE Student Paper, (2011). Participatory radio and the public sphere-the case of climate change communication in Malawi.

White, S. A. (Ed.) (2003). Participatory video images that transform and empower. New Delhi: Sage Publications.

Zhao, X. (2009). Media use and global warming perceptions: A snapshot of the reinforcing spirals. Communication Research, 36(5), 698-723. 
Dr Usha Harris is an academic in the Department of Media, Music, Communication and Cultural Studies at Macquarie University. She has designed and delivered participatory media training in Australia, Fiji, New Zealand and at international conferences (including the case study discussed in this article). Currently, she is developing a new postgraduate unit on Environmental Communication.

usha.harris@mq.edu.au

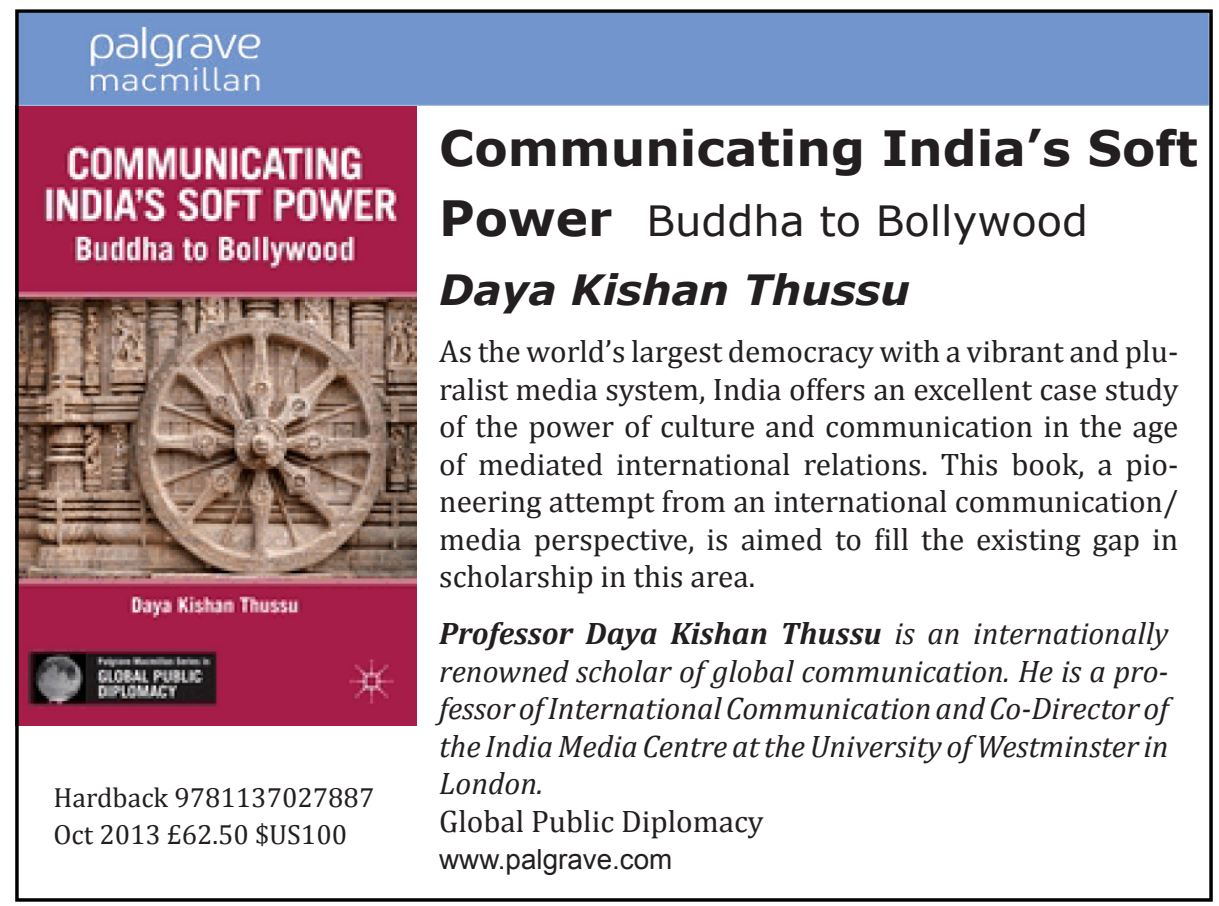

PACIFIC JOURNALISM REVIEW 20 (2) 201495 